\title{
Configurações
}

Revista de sociologia

\section{Introdução: Acolhimento de Crianças e Jovens}

Catarina Tomás, Maria João Leote de Carvalho e Natália Fernandes

\section{OpenEdition}

\section{Journals}

\section{Edição electrónica}

URL: http://journals.openedition.org/configuracoes/6389

DOI: 10.4000/configuracoes.6389

ISSN: 2182-7419

\section{Editora}

Centro de Investigação em Ciências Sociais

\section{Edição impressa}

Paginação: 7-13

ISSN: 1646-5075

\section{Refêrencia eletrónica}

Catarina Tomás, Maria João Leote de Carvalho e Natália Fernandes, «Introdução: Acolhimento de Crianças e Jovens », Configurações [Online], 23 | 2019, posto online no dia 28 junho 2019, consultado o 29 junho 2019. URL : http://journals.openedition.org/configuracoes/6389 ; DOI : 10.4000/ configuracoes.6389 
Introdução - Acolhimento de Crianças e Jovens. Configurações, vol. 23, 2019, pp. 7- 13.

\section{Introdução - Acolhimento de Crianças e Jovens}

CATARINA TOMÁS*

Instituto Politécnico de Lisboa e CICS.NOVA - Centro Interdisciplinar de Ciências Sociais (NOVA FCSH)

MARIA JOÃO LEOTE DE CARVALHO**

CICS.NOVA - Centro Interdisciplinar de Ciências Sociais (NOVA FCSH)

NATÁLIA FERNANDES***

Universidade do Minho, CIEC

Comemorar-se-ão neste ano, em 20 de novembro de 2019, os 30 anos da aprovação da Convenção dos Direitos da Criança (CDC) pela Assembleia Geral das Nações Unidas ratificada pelo Estado português no ano seguinte. Um marco indelével na evolução da história da infância no mundo, marcada por avanços e recuos, cujo impacto em Portugal se fez sentir na reformulação de quadros legislativos de proteção das crianças constituindo-as como sujeitos de direitos. Mais frequentemente do que seria de esperar, a infância continua a ser uma categoria social subalternizada e desvalorizada tanto no campo político como no meio académico ${ }^{12}$,

\footnotetext{
* Docente do Instituto Politécnico de Lisboa, Escola Superior de Educação e Investigadora do Centro Interdisciplinar de Ciências Sociais, da Faculdade de Ciências Sociais e Humanas, da Universidade NOVA de Lisboa. E-mail: ctomas@eselx.ipl.pt

** Investigadora do Centro Interdisciplinar de Ciências Sociais, da Faculdade de Ciências Sociais e Humanas, da Universidade NOVA de Lisboa, a realizar Pós-Doutoramento com apoio da FCT - Fundação para a Ciência e Tecnologia através de Bolsa individual (SFRH/BPD/116119/2016) com financiamento comparticipado pelo Fundo Social Europeu, no âmbito do POCH-Programa Operacional do Capital Humano, e por fundos nacionais do MCTES - Ministério da Ciência, Tecnologia e Ensino Superior. E-mail: mjleotec@ sapo.pt

*** Docente da Universidade do Minho, Instituto de Educação e Investigadora do Centro de Investigação em Estudos da Criança. E-mail: natfs@ie.uminho.pt

1 A nova seção temática "Sociologia da Infância" da Associação Portuguesa de Sociologia (APS), aprovada no final de 2018, dá os primeiros passos. A sua criação veio colmatar uma lacuna desde há muito sentida por sociólogos/as interessados/a nas temáticas da infância e das crianças num contexto de crescente afirmação a nível internacional. Assume-se como um espaço privilegiado de encontro e reflexão, com enfoque particular na especificidade do olhar sobre as crianças, sobre a sua agência, voz e participação, e modos específicos de se construírem enquanto grupo social e não apenas enquanto sujeitos pertencentes a instituições como a escola, a família, a comunidade, entre outras. Consultar: https://aps.pt/pt/seccao-tematica-sociologia-da-infancia/
} 
apenas sobrevalorizada enquanto geração de alunos/as e consumidores que alimenta nichos de mercado.

Apesar da adiada e tardia publicação deste número temático, alheia à vontade de todos os que para ele contribuíram, nomeadamente as suas organizadoras, o seu lançamento, nesta altura, obriga a reafirmar a importância da atualidade deste número, sobre uma temática raras vezes abordada de forma articulada e complementar como aqui se revela. Em novembro de 2018, a intervenção da Secretária de Estado para a Inclusão das Pessoas com Deficiência do XXI Governo, Ana Sofia Antunes, sobre a opção do Estado português em assumir a sua incapacidade em promover a medida de acolhimento familiar de crianças e jovens em perigo por falta de recursos para assegurar a execução dessa medida continuando a privilegiar-se o acolhimento residencial, em detrimento das normas plasmadas na legislação nacional e nas recomendações internacionais, confere a este número uma maior pertinência científica, política e social.

A ausência de uma efetiva retaguarda familiar ou de rede social de apoio na comunidade de origem é um problema social que atravessa os quadros de vida de muitas crianças e jovens, determinando a necessidade do seu acolhimento, sob diversas modalidades. Estima-se que 1\% das crianças residentes no espaço da União Europeia estejam integradas em sistemas de acolhimento, sendo esta proporção variável de país para país (Eurochild, 2010; Petrowski, Cappa, \& Gross, 2017). Conforme previsto em tratados e convenções internacionais, de entre os quais se destaca a Convenção das Nações Unidas sobre os Direitos da Criança (1989), quando temporária ou definitivamente afastados do meio familiar, as crianças e jovens têm direito à proteção do Estado e entre as respostas mais aplicadas destacam-se o acolhimento familiar e o acolhimento residencial.

Os números de crianças e jovens acolhidos não registam tendência para a sua diminuição sendo esta uma problemática relevante tanto do ponto de vista social como científico e político. Pobreza e exclusão social constituem fatores de risco acrescido, sendo que grande parte das crianças e jovens em acolhimento não se insere na categoria "sem família", sendo, sim, oriunda de famílias afetadas por múltiplos fatores de desvantagem social.

A definição de novas geografias no território europeu, aliadas aos fluxos migratórios registados nos últimos anos, impõe novos e complexos desafios nesta área, sendo necessário repensar o conceito de acolhimento, as políticas públicas e as respostas sociais decorrentes, especialmente nos casos das crianças e jovens refugiados que entram na Europa não acompanhados.

A literatura científica (Anglin \& Knorth, 2004; FICE, IFCO \& SOS Children's Villages, 2007; Browne, 2009; UN, 2009; Save the Children, 2010; Csáky, 2014; Chaitkin, Cantwell, Gale, Milligan, Flagothier, O’Kane, \& Connelly, 2017; Carvalho \& Salgueiro, 2018; Pais, 2018) demonstra que as crianças e jovens acolhidos, tanto em famílias de acolhimento como em 
acolhimento residencial, apresentam uma maior probabilidade de vir a ter uma trajetória de vida marcada por situações de desvio, marginalidade e/ou exclusão social do que crianças e jovens não acolhidos (i.e. têm maior probabilidade de virem a experimentar situações como sem abrigo, de cometer crimes, de ter filhos/ as antes de atingirem os 20 anos de idade e de ter os/as seus/as próprios/as filhos/ as acolhidos num percurso de reprodução social). Esta é, pois, uma área em necessidade de permanente evolução e atualização.

Em Portugal, os desenvolvimentos nesta área dão conta de uma revisão significativa da Lei de Proteção de Crianças e Jovens em Perigo, concretizada em 2015 (Lei n. ${ }^{\circ}$ 142/2015, de 8 de setembro, segunda alteração à LPCJP, Lei no 147/99, de 1 de setembro $)^{3}$, a qual vem consagrar o acolhimento familiar como a principal resposta de colocação a assegurar para crianças até aos 6 anos de idade, visando dar cumprimento ao disposto nas normas internacionais. Esta proposta desafia de sobremaneira o atual estado de acolhimento das crianças em Portugal, dada a residual visibilidade desta resposta de acolhimento no panorama nacional, com uma tendência significativa de diminuição dos casos (419 em 2012, 303 em 2015, 261 em 2016, 246 - 3\% do total de acolhimentos - em 2017). Por outro lado, o sistema nacional tem vindo a ser marcado pelo crescente número de jovens adolescentes com problemas de comportamento e de saúde mental, que exigem um conjunto de recursos especializados e um investimento das comunidades e decisores/as políticos/as que venha a traduzir-se numa maior eficácia das respostas implementadas. A investigação produzida neste campo deverá ser considerada nesse investimento e nessa (re)configuração.

É neste âmbito que o atual dossier temático da Revista Configurações reúne um conjunto de nove artigos acerca do "Acolhimento de Crianças e Jovens" que são uma contribuição reflexiva e crítica acerca do fenómeno. Os/as autores/as escolheram maioritariamente os contextos português e brasileiro como âmbito privilegiado para apresentar debates e transformações que foram marcando nas últimas décadas o acolhimento de crianças e jovens. Não obstante, inscrevem-se, na realidade, na discussão e preocupações que, a nível internacional, têm vindo a ser desenvolvidas.

Os artigos aqui reunidos, a partir de uma perspetiva multi e interdisciplinar, centram a sua análise em quatro grandes temáticas: i) as conceções, quer das crianças e jovens, quer das famílias e equipas, sobre temáticas como a autonomização, o acolhimento e/ou reunificação familiar e o acolhimento residencial; ii) a saúde mental das crianças e jovens em acolhimento residencial; iii) a intervenção em contextos de violência doméstica; iv) a reflexão sobre apadrinhamento civil.

No primeiro artigo, de Ana Daniela Silva, Kelly Oliveira e Cátia Marques, analisa-se os discursos de sete jovens em acolhimento residencial sobre percursos de carreira e vivências de autonomização. Os dados obtidos remetem para discursos pautados por sentimentos menos positivos associados à sua experiência 
de acolhimento, pela confusão, falta de agência na tomada de decisão a nível escolar e também falta de alternativas ao acolhimento. As autoras defendem a necessidade de se investir não só na formação das equipas e dos/as psicólogos/ as escolares, no que diz respeito ao apoio e à orientação educativa dos/as jovens em acolhimento residencial, mas também em processos e práticas promotoras de autonomia.

De seguida, João Carvalho, Paulo Delgado e Vânia Pinto, abordam o tema do acolhimento familiar a partir da análise de inquéritos e entrevistas realizadas com 10 casos de acolhimentos no distrito do Porto. Os resultados possibilitam evidenciar a necessidade de se investir na melhoria do sistema de comunicação e a interação entre os/as profissionais, os/as acolhedores/as, as crianças e as famílias de origem; a necessidade de se investir do ponto de vista financeiro junto das famílias de forma a potenciar os encontros com as crianças; e, por fim, compreender que é necessário um longo processo de acompanhamento educativo das várias partes envolvidas. Os/as autores/as destacam neste âmbito o papel fundamental da formação/supervisão.

Paula Costa, Rui Santos e Ricardo Vieira, abordam o tema das experiências de acolhimento residencial e o modo como se desenvolve a (re)construção identitária dos sujeitos acolhidos. Através de uma investigação etnobiográfica, os autores pretendem compreender a perceção dos indivíduos adultos sobre a influência das experiências de acolhimento na (re)construção da sua identidade, desenvolvendo para o efeito estudos de caso biográfico a 4 sujeitos, que em algum momento da sua história de vida viveram em instituições de acolhimento residencial. A pesquisa mostra que o acolhimento residencial permitiu aos entrevistados a aquisição de competências para se transformarem e idealizarem um futuro diferente do dos seus ascendentes, permitindo a estes jovens a aquisição de competências pessoais, sociais, económicas e profissionais, com impacto na sua transformação. O estudo discute, ainda, a identificação, pelos próprios sujeitos estudados, de pessoas e práticas institucionais que reconhecem como fundamentais para todo o processo da sua (re)construção identitária. Conclui que a existência de relações afetivas entre sujeitos e cuidadores/as e técnicos/as das instituições são de extrema importância para o equilíbrio e estabilidade emocional dos sujeitos, como resulta da identificação que fazem das pessoas críticas positivas para a sua vida.

As práticas e visões dos profissionais que trabalham em acolhimento residencial nos processos de reunificação familiar constitui o foco da atenção de José Arizmendi e Ana Almeida. Numa área particularmente sensível em função das necessidades específicas que se colocam à intervenção, a relação estabelecida entre crianças e jovens acolhidos/as, suas famílias e os/as profissionais das casas de acolhimento constitui um fator-chave para a mudança e efetiva promoção do direito à construção de um projeto de vida participado 
e devidamente sustentado. A necessidade de compreender as forças das famílias no contexto de uma avaliação compreensiva impõe-se com o aparecimento de novos instrumentos que permitem especificamente a avaliação de forças e recursos e resulta igualmente da centralidade que assumem os modelos de intervenção multidimensionais. Com o objetivo de identificar melhores respostas às necessidades emergentes das famílias neste tipo de contexto, os/ as autores/as apresentam e debatem os principais resultados obtidos junto de uma subamostra de 27 profissionais de cinco casas de acolhimento no distrito de Braga, que constituem parte de um estudo mais alargado. Analisam as suas perspetivas, os comportamentos, os procedimentos e as atitudes. Os principais resultados revelam a importância de ampliar os recursos, promover a sua formação, especialmente ao nível da sensibilização e promoção da melhoria das competências para o trabalho com as famílias, para que as mesmas sejam efetivamente incluídas nos processos de reunificação. É salientada a necessidade de desenhar procedimentos e planos de ação que, fundamentados na teoria, permitam o trabalho técnico sistemático e a recolha de evidências, uma tendência que não é exclusiva deste campo de análise e antes se estende a todas as áreas da intervenção em acolhimento residencial, exigindo dos profissionais uma permanente atualização de conhecimentos, flexibilização e diversificação de estratégias.

Gabriela Aguiar, Karla e Miriam Rosa apresentam, neste dossier, o debate sobre a institucionalização crianças e adolescentes a partir da realidade brasileira assumindo como enfoque teórico a Psicanálise. Iniciam o artigo com a caracterização das crianças no sistema de acolhimento para, de seguida, defenderem que o acolhimento é atravessado por práticas assentes em discursos estigmatizantes e excludentes que desconsideram as crianças e adolescentes, sobretudo as de classe popular. Alertam, ainda, para a necessidade de considerar na investigação e na intervenção as dimensões psíquicas, afetivas e culturais nos vínculos familiares e a forma como influenciam a constituição psíquica da criança.

Joana Campos, Maria Barbosa-Ducharne, Pedro Dias e Sónia Rodrigues, considerando que o acolhimento residencial é um campo de especial e crescente complexidade que requer o cruzamento de diferentes olhares e saberes científicos, trazem para o aprofundamento do debate nesta área um contributo da Psicologia, que tem como ponto de partida a necessidade de melhor conhecer o panorama atual relativo aos problemas de saúde mental que afetam a população infantojuvenil colocada em acolhimento residencial. No artigo são apresentados e discutidos alguns dos resultados de um estudo exploratório realizado junto de uma amostra de conveniência de 77 crianças colocadas em seis casas de acolhimento em cinco distritos de Portugal. Entre 
os principais resultados, é destacada a existência da presença de sintomatologia psicopatológica nas crianças participantes e a sua relação quer com variáveis da sua história de vida, isto é, as situações de perigo que estão associadas à tomada de decisão sobre a aplicação da medida de promoção e proteção pela responsabilidade que o Estado tem de assumir na proteção das crianças, quer com variáveis relativas às casas que as acolhem, nomeadamente a dimensão e tipologia. Daqui resulta a necessidade de aprofundamento desta reflexão, aos mais variados níveis, importando perceber que implicações esta constatação deve acarretar para a prática profissional em acolhimento residencial.

De seguida, Joana Pires e Paula Cristina Martins analisam a medicação psicotrópica como uma modalidade de intervenção com crianças e jovens em regime de acolhimento residencial em Portugal. A partir do trabalho desenvolvido com 149 crianças e jovens, de idades compreendidas entre 2 e 23 anos, com medida de acolhimento residencial aplicada em 11 casas de acolhimento do concelho de Lisboa, os resultados da investigação confirmaram a elevada prevalência de problemas emocionais e de comportamento, o que remete as crianças e jovens para uma condição de vulnerabilidade. No que diz respeito à prevalência de casos de perturbações de saúde mental diagnosticados, os resultados revelam dados inferiores a estudos de natureza semelhante realizados em outros países. Referem que a intervenção psicofarmacológica não é um recurso frequente ou extensivo nas Casas analisadas, contrariando, desta forma, uma preocupação inicialmente enunciada com a vulgarização, intensificação e relativa indiferenciação da prática de prescrição e administração de fármacos para controlo das crianças e jovens.

Ana Sani e Ana Lúcia Correia apresentam um estudo qualitativo com técnicos que trabalham em casas de abrigo para vítimas de violência doméstica, a intervenção que é desenvolvida junto das crianças que aí, temporariamente, residem. A amostra de onze técnicos, pertencentes a nove casas de abrigo em Portugal, respondeu a uma entrevista estruturada, cujo guião com questões foi disponibilizado eletronicamente.

Os resultados permitem concluir que a intervenção incide, sobretudo, junto das mães, estando fundamentalmente orientada para o treino de competências parentais, vinculação, práticas educativas, regras e rotinas, a usar com os seus filhos. A intervenção direta com as crianças é secundarizada, sendo que as razões invocadas se relacionam com a falta de técnicos, as especificidades do contexto e a formação especializada exigida. $\mathrm{O}$ artigo sublinha a importância de uma ação focada também na criança, visando a promoção do seu bem-estar e desenvolvimento ajustados.

Finalmente, Elisabete Ferreira dá visibilidade ao instituto do apadrinhamento civil, um tema raras vezes abordado no campo das ciências sociais, pouco tratado pela doutrina jurídica e escassamente aplicado. O seu artigo traz para 
discussão as potencialidades e as limitações desta relação jurídica, tendencialmente de caráter permanente, que, em regra, concilia a manutenção de vínculos biológicos com os vínculos afetivos típicos do apadrinhamento. Um instrumento concebido no ordenamento jurídico português em 2009 que pretende constituir uma alternativa ao acolhimento residencial de longa duração ao visar proporcionar às crianças cujos progenitores, por qualquer razão, não exerçam da forma mais adequada as suas responsabilidades parentais, a promoção do seu bem-estar e desenvolvimento através da ação de um padrinho civil que se encontra habilitado a exercer o essencial das responsabilidades parentais, em diálogo com os pais, relativamente aos aspetos mais relevantes da vida e da pessoa da criança. Apesar da componente inovadora desta medida para a construção dos projetos de vida e proteção dos direitos da criança acolhida, numa linha de orientação similar relativamente ao que é aplicado noutros países, a autora conclui pela necessidade da sua (re)descoberta, divulgação e dinamização, tanto no plano do Direito como junto das comunidades e profissionais intervenientes nos processo de promoção e proteção, para que possa vir a traduzir-se numa efetiva alternativa ao acolhimento residencial, como se encontra já traduzido no campo jurídico. O desfasamento entre o disposto na lei e as práticas sociais e jurídicas constitui o cerne da reflexão aqui apresentada.

\section{Referências bibliográficas}

ANGLIN, J. \& KNORTH, E. (2004). Competing declarations on residential care for children and youth - Stockholm versus Malmö: International perspectives on rethinking residential care, Child \& Youth Care Forum, 33(3), 141-149.

BROWNE, K (2009). The risk of harm to young children in institutional care, London: Better Care Network and Save the Children.

CARVAlho, M.J.L \& SAlgueiro, A. (2018). Pensar o Acolbimento Residencial de Crianças e Jovens, Lisboa: Fundação Calouste Gulbenkian.

CHAitKin, S., CANTWell, N., GAle, C., Milligan, I., FlagOthier, C., O'KANE, C. \& CONNELLY, G. (2017). Towards the right care for children, Luxembourg: European Union.

CSÁKY, C. (2014). Why Care Matters: The importance of Adequate Care for Children and Society, London: Family For Every Child.

FICE, IFCO \& SOS Children's Villages (2007). Quality4Children: Normas para o Acolhimento de Crianças Fora da Sua Família Biológica na Europa, Innsbruck: Werner Hilweg, Áustria. Disponível em: http://quality4children.info/navigation/show.php3?id=2\&_language=en.

EUROCHILD (2010). Children in Alternative Care-National Surveys, Bruxelles: Eurochild Publications.

PAIS, M.S. (2018). "Acolhimento residencial de crianças e jovens: protege, prevenir e capacitar". In M.J.L., Carvalho \& Salgueiro (Eds.), Pensar o Acolhimento Residencial de Crianças e Jovens, Lisboa: Fundação Calouste Gulbenkian, pp. 13-19.

PETROWSKI, N.; CAPPA, C.; \& GROSS, P. (2017). Estimating the number of children in formal alternative care: Challenges and results, Child Abuse \& Neglect, vol.70, 388-398.

SAVE THE CHILDREN (2010). Building rights-based national child protection systems: A concept paper to support Save the Children's work, Sweden: Save the Children.

UN - United Nations General Assembly (2009). United Nations General Assembly Guidelines for the Alternative Care of Children, UN document A/RES/64/142 United Nations, Geneva, http:// www.unicef.org/protection/alternative_care_Guidelines-English.pdf 